\title{
Coastline Management: Review and Countermeasure Proposal
}

\author{
HUO Suxia ${ }^{1,2}$, WANG Guogang ${ }^{3, a^{*}}$, XIU Chun ${ }^{1,2, b^{*}}$, ZHANG Tianyu ${ }^{1,2}$, CHEN Keke ${ }^{1,2}$ \\ ${ }^{1}$ North China Sea Environmental Monitoring Center, SOA, 266033 Qingdao, China \\ ${ }^{2}$ Shandong Province Key Laboratory of Marine Ecology and Environment \& Disaster Prevention and Mitigation, 266061 Qingdao, \\ China \\ ${ }^{3}$ Shandong Municipal Oceanic Bureau, 250002 Jinan, China
}

\begin{abstract}
The scientific coastline management is of great significance to the development of marine economy, coordinated development of land and marine and construction of ecological civilization. The coastline management in China has experienced two main stages: (i) the stage of basic survey and jurisprudential establishment, and (ii) the stage of perfection under new situation. There are challenges in promoting modern marine governance and marine power, which are characterized by the lack of high-quality management involvement throughout the coastline management process. Accordingly, coastline supervision is not comprehensive, the standardized system still needs to be improved, and the research on the main function of coastline has not been conducted yet. On this basis, the corresponding strategies were put forward from the perspectives of top-level design, main function, the "double-index" assessment system, requisition-compensation balance of natural coastline, with a view to provide strategic support for coastline management in China.
\end{abstract}

\section{Introduction}

As the boundary between land and sea, coastline not only provides resources and natural ecological landscape for production development and life services, but also carries rich environmental information, which is significant for coastal beach, wetland ecosystem and coastal marine environment. The protection and rational utilization of coastline are not only vital to the healthy development of coastal cities, but also affect the safety of marine natural environment. In recent years, China has paid great attention to coastline management by introducing a series of policy documents and issuing restrictive indicators based on coastline protection. It provides an irreplaceable guiding and leading role in the current and will do it in the future coastline management. After the national structure reform in China, the Ministry of Natural Resources, which performs the duty of "two unifications", has launched a new round of coastline surveys, actively expanding and enriching the connotation of coastline management with the delimitation of coastline location as a breakthrough point. At present, it is in the critical period for the formulation of the " $14^{\text {th }}$ Five-Year Plan" that represents a development plan with the integration period for the unified management of natural resources. Accordingly, it is important to carry out the research on coastline management and development strategies to maintain national defense security, the stability of production and life of the public, and the marine ecological security.

\section{Review of coastline management}

\subsection{The stage of basic survey and jurisprudential establishment}

This stage mainly involves theoretical research on coastline, revision survey, and the formulation of "Administration law of sea area use" (Table 1). The coastline survey of P. R. China was first conducted by the Navy surveying and mapping department 1 . Furthermore, the first comprehensive survey of coastal zone and coastal beach resources nationwide was carried out with the approval of the State Council in the 1980s 2. In 2007, the former State Oceanic Administration organized and carried out the "Special Project on Comprehensive Offshore Marine Survey and Evaluation in China", which made out offshore environmental resources in China, involving the mainland coastline revision survey. Few of the coastal provinces successively published the results of coastline survey. Scholars have conducted in-depth research on coastline classification, location delimitation and survey technology 3-6. A series of national or industrial standards were formulated that relate to coastline in marine surveying and mapping, marine geology and other fields. This provided a basis for the development of various basic surveys and a solid 
theoretical and standard foundation for coastline management. For the first time, the "Administration law of sea area use" promulgated and implemented in 2002 has given legal effect to the coastline, i.e. inland waters that denote to the sea area from the landward side of the territorial sea baseline of the people's Republic of China to the coastline.

Table1. Documents on coastline management or investigation

\begin{tabular}{|c|c|c|c|}
\hline Number & Name & $\begin{array}{c}\text { Issuing } \\
\text { time }\end{array}$ & Type \\
\hline 1 & $\begin{array}{c}\text { Administration law of } \\
\text { sea area use }\end{array}$ & 2002 & Law \\
\hline 2 & $\begin{array}{c}\text { Management Measures } \\
\text { for Coastline Protection } \\
\text { and Utilization }\end{array}$ & 2017 & $\begin{array}{c}\text { Policy } \\
\text { document }\end{array}$ \\
\hline 3 & $\begin{array}{c}\text { Technical Specifications } \\
\text { for Coastline Survey } \\
\text { Statistics }\end{array}$ & 2018 & $\begin{array}{c}\text { Technical } \\
\text { specification }\end{array}$ \\
\hline 5 & $\begin{array}{c}\text { Technical Specifications } \\
\text { for Coastline Survey }\end{array}$ & 2019 & $\begin{array}{c}\text { Technical } \\
\text { specification }\end{array}$ \\
\hline 5 & $\begin{array}{c}\text { Technical Specifications } \\
\text { for Coastline Survey in } \\
\text { China }\end{array}$ & 2019 & $\begin{array}{c}\text { Technical } \\
\text { specification }\end{array}$ \\
\hline
\end{tabular}

\subsection{The stage of development and improvement under the new situation}

In this stage, China focused on the objective to become a maritime power, and adhered the five development concepts, so as to govern the sea by law and manage the sea in an ecological manner. In 2012, the State Council successively approved the marine function zoning of 11 coastal provinces (autonomous regions or municipalities directly under the Central Government), with the target of natural coastline retention rate mentioned. This was the first time that the coastline survey results of "the special project of comprehensive coastal investigation and evaluation in China" had been applied in the plan approved by the State Council, and the coastline was upgraded to a national-level constraint index. In November 2016, the central leading group for "comprehensively deepening reform" delivered and approved Management Measures for Coastline Protection and Utilization, which was the first normative document targeting coastline management in China, thus making up for the recognized gap in this sector 7 , and establishing the management mechanism with the natural coastline retention rate as the core. To implement Management Measures for Coastline Protection and Utilization, the former State Oceanic Administration launched coastline survey and statistics nationwide in May 2017, thus laying the foundation for the formulation of coastline management policies and a new round of coastline survey under the new situation. The requirement of coastline protection was mentioned again in Notice on Strengthening Coastal Wetland Protection and Strictly Controlling Sea Reclamation ([2018] No. 24 document from the State Council) issued by the State Council, with the aim of "ensuring that the area of marine ecological protection redline will not be reduced, the standard for mainland natural coastline retention rate will not be lowered, and the length of existing sandy coastline of islands will not be shortened". Under the influence of human and natural factors, the location of coastline has substantially changed over the past decade. A new round of coastline survey was fully launched in 2019, and it is currently in the stage of results verification. It can be seen that the development and improvement of coastline management under the new situation has further enriched the connotation of natural resource management, standardized the management of land and sea resources, and promoted the development of marine economy.

\section{Problems and challenges}

Coastline management not only focuses on space resources and ecological environment, but also must ensure the national strategic layout, healthy economic development and living demands of the public. Although coastline management has been moving forward through exploration, it still pursues one-sidedly coastline length and natural coastline retention rate, but neglects the management of the ecological function of coastline, the quality management of natural coastline $\mathrm{e}$ and the important role of the positioning of main coastline function in promoting the development of marine economy. These actions do not match the capacity and requirements of modern governance, the positioning and requirement of a maritime power, or the overall goal of comprehensively deepening reform. These are also the major challenges and opportunities for China in the process of promoting the marine power and the modernization of marine governance.

\subsection{The concept of high-quality management has not been thoroughly involved in the whole process of coastline management}

The high-quality development of coastline is the inevitable requirement for implementing the new development concept, and fundamentally establishing the concept of high-quality management is the premise for implementing the transformation of high-quality management modes. High-quality management concept should always be involved thoroughly from formulation of the policy and standard, basic survey, location revision to development and utilization, system assessment, supervision and assessment. At the present stage, only intensive and efficient requirements have been put forward for the development and utilization of coastline, yet other links are lacking. Accordingly, it does not meet the requirements of fine management and high-quality development.

\subsection{The supervision and assessment means of coastline management are too single}

At present, the main supervision and assessment means of coastline management usually involve only the index of natural coastline retention rate. The natural coastline retention rate is only the characterization for the length of 
natural coastline, which cannot reflect whether the natural morphological characteristics of natural coastline are complete or not, and cannot objectively reflect whether the ecological function of natural coastline is healthy or not. Accordingly, by only considering the natural coastline retention rate as the assessment index will have a certain limitation as it cannot comprehensively and objectively reflect the development and utilization intensity, health status, governance ability and management level of the coastline. Besides, subject to objective factors, the target of natural coastline retention rate is not easy to be decomposed. Therefore, it is urgent to explore other effective coastline assessment indicators on the basis of assessment indicators for natural coastline retention rate, in order to comprehensively evaluate the actual management level of coastline.

\subsection{The standard and specification system of coastline is not perfect enough}

The development of the standard and specification should be involved in the process of coastline management, which should be taken as an important part in serving the fine management of coastline. At present, there are relatively few standards and specifications specifically for coastline. The national regulations mainly include Technical Specifications for Coastline Survey (a special project for comprehensive investigation and evaluation of offshore ocean in China, 2007) and Technical Specifications for Coastline Survey in China ([2019] No. 1187 issued by General Office of the Ministry of Natural Resources). Local standards mainly include Technical Specifications for Coastline Survey (DB 37/T 3588-2019) in Shandong, Technical Specifications for Coastline Survey Statistics (DB 33 / T 2106-2018) in Zhejiang, etc. These standards and specifications involve the definition of coastline, location and type defining of coastline, the division of its development and utilization, etc. However, the standards and specifications for protection, main function, quality evaluation and value evaluation are lacking. At present, no systematic database with stronger pertinence, wider coverage and better intersectionality is established.

\subsection{Research on the main function of coastline has not been carried out}

Each section of coastline has many functions with only one as main function. Dividing the main functional area is important for natural resources management of land and sea. By dividing the main functions of different coastlines, we can realize the differentiated development mode, optimize and adjust the layout of coastal economy, and promote industrial upgrading. At present, coastline research is mainly focused on the location definition and type division. The concept of main function has not been introduced, and there are still gaps in the introduction of main function concept and research on main functions. The protection and utilization work of coastline guided by the orientation of main function has not been carried out. This is the biggest weakness in coastline management, which needs to be studied and resolved urgently.

\section{Strategies and suggestions}

Regarding coastline management under the new situation, Management Measures for Coastline Protection and Utilization should be taken as the guiding principle. The new concept should be followed to lead to the high-quality development of coastline management, promoting the expansion of coastline management from natural attribute-dominated management to that based on both social and natural attributes. Furthermore, it should promote the extension of coastline management from the single space resource management to the comprehensive marine economic management, thus realizing the new breakthroughs, promotion and development in coastline management. Thus, it is suggested to conduct in-depth research from different perspectives presented in the following subsections.

\subsection{Research on the top level design of coastline}

Management Measures for the Protection and Utilization of Coastline are the basis for coastline management. It is necessary to strengthen the research based on the top-level design from the policy, standard system, planning, use control, assessment and other perspectives as well as to combine several management elements to establish a comprehensive coastline management system.

\subsection{Research on main functions of coastline}

Delimiting the main function of coastline is an important prerequisite for establishing spatial planning of land and conducting the renovation and restoration of coastline. On the basis of implementing the natural attribute management of coastline, we should strengthen the social attribute management of coastline from the perspective of harmony between humans and nature. The evaluation and analysis should be focused on the bearing capacity, development intensity and potential of the coastline, and the factors such as population distribution, economic layout, and comprehensive utilization of land and sea. Furthermore, ecological environment protection in coastal areas should be comprehensively considered in delimiting the functional units of the coastline and laying out the ecological coastline, production coastline and living coastline. This also indicates the effort to implement the theoretical connotation of the "Two Mountains Theory". By paying particular attention to the transformation of natural attribute-dominated management to that based on both social and natural attributes, the main function of coastline is oriented towards the coordinated management of land and sea, and to active promotion of coastline protection and ecological civilization. 


\subsection{Research on "administrative coastline" and "natural coastline"}

An important administrative function of coastline is to adopt the management boundary by sea management law and land management law. As a legal management boundary, even the small adjustment and alteration will have a significant impact on the administration, ownership management, natural resource management, etc. Meanwhile, the implementation of double-line mode of "administrative coastline" and "natural coastline" should be taken into consideration to solidify the "administrative coastline" in law, maintain the management of land and sea, and protect the legal rights of the administrative counterpart. Meanwhile, the management of "natural coastline" should be strengthened by providing protection of the mean high tide line. Regular surveillance and monitoring should be carried out supplemented by statistical analysis of the length, type and natural coastline retention rate.

\subsection{Research on "double index" assessment system for coastline}

Establishing a scientific and reasonable assessment system for coastline management is a guarantee for implementing comprehensive coastline management. In Management Measures for the Protection and Utilization of Coastline is clearly proposed that "the assessment indices should be reasonably determined, and the protection of natural coastline should be involved in the political achievement assessment of local people's governments in coastal areas". Due to different economic development levels and protection measures in coastal areas, the existing natural coastline retention rate varies greatly from less than $5 \%$ to more than $45 \%$. At present, only natural coastline retention rate is taken as the assessment index, which pays attention to the length of the natural coastline and ignores its overall quality. On the basis of the natural coastline retention rate index, we should introduce a multidimensional analysis framework that will comprehensively consider the natural environment, economic development, life services and other factors. Furthermore, the framework should reasonably design the weight, establish the quality assessment index for coastline, and construct the "double index" assessment system for coastline in order to ensure the manageable and controllable protection and rational utilization of the coastline.

\subsection{Research on the requisition-compensation balance mechanism of natural coastline}

Under the influence of location factors and unbalanced economic development, large differences in the protection and utilization of coastline exist in different regions or within the same region that result in significant differences in the existing natural coastline reserves between regions. At the same time, the protection of natural coastline in a certain area also faces various pressures. The goal of natural coastline retention rate is the bottom line for coastline protection and the red line in coastline development and utilization. In view of this, requisition-compensation balance of natural coastline should be taken as an important lever for keeping the objective of natural coastline retention rate and promoting coordinated regional development. We should speed up the research on the requisition-compensation balance mechanism of natural coastlines, formulate standards for the requisition-compensation balance for different types of coastlines, explore diversified modes of capital and restoration compensation, and implement differentiated management to ensure that the retention rate of natural coastlines and the overall quality of coastlines will not be reduced.

\subsection{Research on annual surveillance and monitoring of coastline}

Mastering the real-time data on coastline is an important basis for the management of coastline. Obtaining coastline data is a long-lasting work, which cannot be completed only through five or ten-year survey. Based on the favorable conditions of the new round of coastline survey results, several actions should be performed: (i) the annual coastline survey and evaluation mechanism should be established; (ii) the coastline survey and assessment system should be improved; (iii) the stability of natural coastline should be comprehensively analyzed; (iv) the length and quality of natural coastline should be objectively evaluated; and (v) the potential ecological restoration coastline should be selected to provide scientific data for the protection and rational utilization of various levels of coastlines.

\subsection{Research on the objectives of natural coastline retention rate}

In Management Measures for Coastline Protection and Utilization, the objectives of natural coastline retention rate for different provinces by the end of 2020 have been clearly stipulated. At present, departments at all levels are actively conducting research on the formulation of the "14th Five-Year Plan" and formulating the land spatial planning at three levels of provinces, cities and counties, in which the natural coastline retention rate is an important planning index. Scientifically calculating the natural coastline retention rate in the near, medium and long term is of significance to strengthen the construction of ecological civilization and promote the development of marine economy. The rigid control of coastline protection and the elastic prediction of its development and utilization should be handled in a dialectical manner. From the aspect of actual situation, we should neither deviate from the reality because of setting too high objectives, nor violate the concept of ecological civilization because of setting too low objectives. Special research should be carried out based on the results from the new round of coastline revision survey and annual coastline supervision and monitoring, and in combination with the basic situation of coastal 
areas, major infrastructure layout, and renovation and restoration plan. Furthermore, the control targets of natural coastline retention rate in the next five or ten years should be calculated, thus keeping the ecological bottom line of natural coastline for the public and reserving reasonable space for future development.

\section{Conclusions}

The coastline management in China has gone through two stages: the stage of basic investigation and jurisprudential establishment, and the stage of development and improvement under the new situation. At present, coastline management in China still faces challenges, such as the fact that the concept of high-quality management has not been involved throughout the whole process of coastline management, the means of coastline supervision and assessment is too single, the scientific and reasonable standard and specification system still needs to be improved, and the research on the main function of coastline has not been carried out. In the process of promoting marine power and modern marine governance, research can be carried out from the perspectives of top-level design, main function, "double index" assessment system, requisition-compensation balance of natural coastlines in order to provide strategic support for improving the coastline management system in China.

\section{Acknowledgements}

This paper was supported by the Marine Science and Technology Project of North China Sea Bureau of Ministry of Natural Resources (No. 202004) and Ocean Management Committee Project of PSC (No. 201705).

\section{References}

1. JIA, J. J., CAI, T. L., LIU, Y. F., CHEN, Y. N., WANG, X. K., MEI, Y. P., SHI, L. Q., XIA, X. M. (2019) A classification of coastline considering the impacts of human activities: remarks on latest practices on coastline survey in Zhejiang Province. Marine Sciences, 43: 13-23.

2. SU, J. S. (1988) A review of the comprehensive survey of coastal zone and tidal flat in China in the past seven years. Ocean Development and Management, 30-32.

3. ZHAO, M. C., ZHANG, D. C. (1990) Discussion on the definition of shoreline. Coastal Engineering, 9: 91-99.

4. LIN, G., L., ZHENG, Y., L. (2008) Discussion on some techniques of coastline survey. Ocean Development and Management, 25: 61-67.

5. XIA, D. X., DUAN, Y., WU, S. Y. (2009) Study on the methodology of recent coastline delimitation. JOURNAL of MARINE SCIENCES, 27: 28-33.

6. WANG, C. H., QIU, J. F., DING, H. (2009) On the coastline issues in sea area utilization. Ocean Development and Management, 26: 51-56.

7. PAN, X. C., YANG L. (2017) Protect the coastline by classification and maintain the ecological function of coast: an interpretation of regulations on coastline protection and utilization management, 34 : 3-6. 